\title{
Authors / Autoras y autores
}

Anna M. Brígido-Corachán es Profesora Titular de Literatura Norteamericana y Postcolonial en la Universitat de València. Su investigación está centrada en el estudio de las literaturas indígenas de Norteamérica, especialmente en la reescritura histórica y las prácticas de reespacialización y resistencia de la novela amerindia contemporánea en Estados Unidos y México. Otros focos de interés académico son la representación de las minorías étnicas en la literatura y el cine contemporáneos, los nuevos movimientos sociales y el relato digital. Actualmente coordina el proyecto de innovación universitaria sobre pedagogía crítica NAPCED y es miembro de la red interuniversitaria Small/Minor Literatures. Ha publicado más de una veintena de artículos, libros y capítulos de libro en revistas científicas y volúmenes especializados y recientemente ha coeditado el número monográfico 21st Century American Crises: Reflections, Representations, Transformations en la revista Studies in the Literary Imagination (2017) a la par que sigue completando las últimas revisiones de su manuscrito Redrawing the Americas, bajo contrato con la University of Nebraska Press.

Nora Catelli se licenció en Letras en la Universidad Nacional de Rosario (Argentina) y es doctora en Filología Hispánica; actualmente es profesora titular de teoría literaria y literatura comparada en la Universidad de Barcelona. Ha sido crítica literaria en La Vanguardia, El País y en varias revistas. Es autora de numerosos trabajos sobre teoría y pensamiento literario, especialmente en teoría de la autobiografía, historia y teoría de la traducción y de la lectura. Es autora, entre otros, de El espacio autobiográfico (Lumen, 1991), y, en colaboración con Marietta Gargatagli, El tabaco que fumaba Plinio -escenas de la traducción en España y América: relatos, leyes y reflexiones sobre los otros (Ediciones del Serbal, 1998); Testimonios tangibles -Pasión y extinción de la lectura en la literatura moderna (Barcelona, 2001, XXIX Premio Anagrama de ensayo). En el 2016 ha sido galardonada con el Premio de la fundación Konex en la categoría Teoría Lingüística y Literaria.

Guillermina De Ferrari es profesora de Literatura Caribeña y Cultura Visual en la Universidad de Wisconsin-Madison. Es autora de Vulnerable States: Bodies of Memory in Contemporary Caribbean Fiction (2007), Community and Culture in Post-Soviet Cuba (2014; en español 2017) y de Apertura: Photography in Cuba Today (2015). Es una de las coeditoras de Futures of Comparative Literature (2017). Es coeditora del dossier Caribbean Hauntologies Vournal of Latin American Cultural Studies, 2018) y codirige (con Ursula Heise, UCLA) la serie Literature and Contemporary Thought (Routledge). Actualmente es Senior Fellow en el Instituto de Humanidades de la Universidad de Wisconsin-Madison.

César Domínguez es profesor titular de literatura comparada en la Universidad de Santiago de Compostela, donde ha sido titular de la Cátedra Jean Monnet "La cultura de la integración europea” entre 2012 y 2015. Desde 2016 es asimismo catedrático honorario de literatura comparada en la Universidad de Sichuan. Su docencia e investigación se centran en teoría de la literatura comparada, literatura europea, traducción, cosmopolitismo, migración y literatura mundial. Sus libros más recientes son, entre otros, World Literature: A Reader (Routledge, 2013), Contemporary Developments in Emergent Literatures and the New Europe (Universidad de Santiago de Compostela, 2014) e Introducing Comparative Literature: New Trends and Applications (Routledge, 2015), traducido recientemente al castellano por Taurus y al árabe 
por el Consejo Nacional de Cultura de Kuwait. En la actualidad es vicepresidente de la Sociedad Española de Literatura General y Comparada, y, entre otros, asesor del Instituto de Literatura Mundial de la Universidad de Harvard.

Gustavo Guerrero es profesor de literaturas y culturas latinoamericanas contemporáneas en la Universidad de Cergy-Pontoise/Paris Seine y en la Escuela Normal Superior de Paris. También es consejero literario para la lengua española de la casa Gallimard. Entre otras, editó, junto a François Wahl, las Obras completas (Madrid, 1999) del cubano Severo Sarduy en la colección Archivos-Unesco. Ha publicado varios ensayos, entre otros "Historia de un encargo: La catira de Camilo José Cela" (2008), con la que obtuvo el XXXVI Premio Anagrama de Ensayo. Su última publicación es Paisajes en movimiento, literatura y cambio cultural entre dos siglos (Eterna Cadenia, 2018). Fue profesor invitado del Programa de Estudios Latinoamericanos de la Universidad de Princeton en 2009 y 2010, y de la Universidad de Cornell en 2014. Actualmente es profesor invitado de la Universidad de Berna.

Héctor Hoyos es profesor del Departamento de Culturas Iberoamericanas de la Universidad de Stanford y doctor en Estudios Románicos por la Universidad de Cornell. Es autor del libro Beyond Bolaño: The Global Latin American Novel (2015). Editó los números especiales "Theories of the Contemporary in South America" para la Revista de Estudios Hispánicos (2014) y "La cultura material en las literaturas y cultura iberoamericanas de hoy" para Cuadernos de literatura (2016). Su manuscrito actual, Things with a History: Transcultural Materialism in Latin America, por el cual ha recibido una beca Alexander von Humboldt, será publicado por Columbia University Press. Enseñará un curso al respecto en el Instituto de Literatura Mundial de la Universidad de Harvard en 2019.

Alejandra Laera es Profesora Titular de Literatura Argentina en la Universidad de Buenos Aires e Investigadora Independiente del Consejo Nacional de Investigaciones Científicas y Técnicas (CONICET). Ha sido profesora visitante en universidades de su país y del exterior. Es autora de El tiempo vacío de la ficción. Las novelas argentinas de Eduardo Gutiérrez y Eugenio Cambaceres (Fondo de Cultura Económica, 2004) y de Ficciones del dinero. Argentina, 18902001 (FCE, 2014), y directora de El brote de los géneros (Emecé, 2010), tercer tomo de la Historia crítica de la literatura argentina. Realizó diversas ediciones de clásicos argentinos (como Juan Moreira y Facundo) y coeditó varios volúmenes colectivos. Además, dirige la serie Viajeros para el FCE y codirige la Maestría de Periodismo Narrativo de la Universidad Nacional de San Martín.

Jorge J. Locane es licenciado en Letras por la Universidad de Buenos Aires y Dr. Phil. por la Universidad Libre de Berlín. Su tesis doctoral fue publicada bajo el título Miradas locales en tiempos globales (Iberoamericana/Vervuert, 2016). En los últimos años se ha desempeñado como investigador postdoctoral en el proyecto "Reading Global. Constructions of World Literature and Latin America", de la Universidad de Colonia, de donde han surgido su monografía De la literatura latinoamericana a la literatura (latinoamericana) mundial (De Gruyter, 2019), dedicada a la (no) circulación internacional de literatura y a las políticas editoriales, y el volumen colectivo, editado con Gesine Müller y Benjamin Loy, Re-mapping World Literature. Writing, Book Markets and Epistemologies between Latin America and the Global South (De Gruyter, 2018). Es cofundador de la revista bilingüe alba. lateinamerika lesen y autor de dos poemarios. 
Benjamin Loy es profesor asistente en el Departamento de Lenguas y Literaturas Románicas de la Universidad de Colonia y doctor en Estudios Románicos por la Universidad de Potsdam. Su tesis de doctorado "La biblioteca salvaje: estéticas y políticas de la lectura en la obra de Roberto Bolaño" se publicará en 2019 e investiga las múltiples relaciones intertextuales con numerosos autores de la literatura mundial en la obra de Roberto Bolaño. Sus intereses de investigación y publicaciones se centran en literaturas latinoamericanas, española y francesa modernas y contemporáneas, cine latinoamericano y aspectos teóricos y prácticos de la literatura mundial. Última publicación aparecida en co-edición con Gesine Müller y Jorge Locane: Re-mapping World Literature. Writing, Book Markets, and Epistemologies between Latin America and the Global South (De Gruyter, 2018).

Gesine Müller es titular de la cátedra de Romanística de la Universidad de Colonia y directora del grupo de investigación "Reading Global. Constructions of World Literature and Latin America”, fundado por el Consejo de Investigación Europeo (ERC). De 2008 a 2015 fue directora del grupo de investigación "Caribe transcolonial" financiado por el programa EmmyNoether de la DFG. Sus principales focos de interés han sido: literatura romántica en Francia y España, literaturas latinoamericanas contemporáneas y teoría cultural, literaturas caribeñas, procesos de transferencia literaria y transculturalidad. Entre sus publicaciones se puede mencionar entre otros: Crossroads of Colonial Cultures. Caribbean Literatures in the Age of Revolution (De Gruyter, 2018); Re-mapping World Literature. Writing, Book Markets and Epistemologies between Latin America and the Global South, (co-edición con Benjamin Loy y Jorge J. Locane, De Gruyter, 2018); América latina y literatura mundial. Mercado editorial, redes globales y la invención de un continente (co-edición con Dunia Gras, Iberoamericana, 2015), Verlag Macht Weltliteratur (edición en tranvía, 2014).

Alexandra Ortiz Wallner es doctora en Literaturas Romanes (Potsdam) e investigadora de la Fundación Alemana de Investigación Científica (DFG) en la Universidad Libre de Berlín con un proyecto sobre modernidad, orientalismos y archivo en intelectuales heterodoxos en el Sur global (América Latina e India). Ha sido profesora invitada de literaturas hispánicas en Berlín, Nantes, Barcelona, Delhi y Chile. Especialista en narrativa centroamericana, es autora de $\mathrm{El}$ arte de ficcionar: la novela contemporánea en Centroamérica (Vervuert/Iberoamericana, 2012) y coeditora de varios volúmenes en estudios centroamericanos. Su más reciente libro Sur/South. Poetics and Politics of Thinking Latin America/India (con Susanne Klengel, Iberoamericana, 2016) ha sido incluido en Oxford Bibliographies como una de las obras introductorias de referencia para el campo de los estudios culturales y literarios sobre el Sur global.

Marta Puxan-Oliva es investigadora postdoctoral en los Estudis d'Arts i Humanitats de la Universitat Oberta de Catalunya y profesora asistente en el Departamento de Lenguas y Literaturas Modernas y Estudios de Inglés de la Universitat de Barcelona. Se especializa en teoría narrativa, racial studies y literatura mundial. Ella tuvo una beca Marie-SkłodowskaCurie en el Departamento de Literatura Comparada de la Universidad de Harvard (2012-2015) y en el Departamento de Lenguas y Literaturas Románicas en la Universitat de Barcelona (2015-2016). Actualmente está trabajando en un proyecto sobre océanos y literatura desde una perspectiva comparativa y global. Ha publicado, entre otros, artículos en revistas como Atlantis y The Journal of Narrative Theory y coeditó con Annalisa Mirizio, el número especial "Rethinking World Literature Studies in Latin American and Spanish Contexts" del Journal of 
World Literature (2017). El manuscrito de su libro, Narrative Reliability, Racial Conflicts, and Ideology in the Modern Novel está en revisión en De Gruyter.

Ignacio M. Sánchez Prado es titular de la cátedra Jarvis Thurston y Mona van Duyn en las Humanidades en Washington University in St. Louis. Su investigación se enfoca en la relación entre estética, ideología e instituciones culturales con un enfoque particular en literatura y cine. Es autor de seis libros entre los que se incluyen Screening Neoliberalism. Transforming Mexican Cinema 1988-2012 (2014), y Strategic Occidentalism. On Mexican Fiction, The Neoliberal Book Market and the Question of World Literature (2018) asi como Intermitencias alfonsinas. Estudios y otros textos (2004-2018), de próxima aparición. Ha editado trece colecciones críticas, ente ellas A History of Mexican Literature (con Anna Nogar and José Ramón Ruisánchez, 2016), Mexican Literature in Theory (2018) and Pierre Bourdieu in Hispanic Literature and Culture (2018). Ha publicado más de ochenta artículos sobre literatura, cine y cultura mexicanos y teoría cultural.

Mariano Siskind es Profesor de Lenguas y Literaturas Romances y Literatura Comparada en Harvard University. Ha publicado más de treinta artículos y ensayos en revistas especializadas y volúmenes críticos. Escribió Cosmopolitan Desires. World Literature and Global Modernity in Latin American (Northwestern University Press, 2014; traducido por Fondo de Cultura Económica en 2016), y en 2019, Northwestern University Press publicará su libro About the End of the World: The Demise of Cosmopolitanism in Contemporary Culture. Seleccionó los textos y escribió un estudio crítico para el libro de Homi K. Bhabha, Nuevas minorías, nuevos derechos. Notas sobre cosmopolitismos vernáculos (2013); co-editó con Sylvia Molloy Poéticas de la distancia. Adentro y afuera de la literatura argentina (Norma, 2006), y junto con Guillermina De Ferrari, The Routledge Companion to Latin American $20^{\text {th }}$ and $21^{\text {st }}$ Century Literature and Cultural Forms (que aparecerá en 2020). Espera poder publicar a finales de 2019 un libro que creyó haber terminado ya dos veces (con resultados poco felices en ambas ocasiones), Latin American Literature and the Great War: On the Globality of World War I.

Alejandra Uslenghi es Profesora Asociada en el Departamento de Español y Portugués y en el programa de Estudios de Literatura Comparada en la Universidad de Northwestern, US. Ahí es profesora en el programa de Teoría Crítica y participa en el proyecto de la fundación Andrew Mellon "ICCTP Critical Theory in the Global South Project". Es autora de Latin America at finde-siècle Universal Exhibitions. Modern Cultures of Visuality (Palgrave, New Directions in Latino American Cultures, 2016) y editora del volumen Walter Benjamin. Culturas de la imagen (Eterna Cadencia, 2011). Co-editó el número especial de Journal of Latin American Cultural Studies sobre fotografía moderna en Argentina, "Horacio Coppola and Grete Stern" (2015). Su investigación se centra en la relación entre la literatura moderna y la cultura visual; la fotografía y el arte contemporáneo en Latinoamérica; y trabaja especialmente en teoría crítica y estudios modernistas comparados. Actualemnte se encuentra trabajando en su segundo libro que examina la intersección entre la experimentación literaria modernista y la fotografía, con énfasis en las fotógrafas del siglo XX en Latinoamérica. 